\title{
O Projeto do Submarino Nuclear Brasileiro*
}

João Roberto Martins Filho**

Desde fins de 1978, o Brasil resolveu investir em um programa tecnologicamente autônomo de construção de um submarino de propulsão nuclear, que, quando completado, incluiria o país no clube restrito das nações capazes de construir esse tipo de equipamento. Tomada à época do regime militar e no contexto do Acordo Nuclear BrasilAlemanha de 1975, a decisão visava, sobretudo, possibilitar o controle das tecnologias de enriquecimento do urânio e de construção de reatores para propulsão naval submarina. À época da concepção do projeto, sua justificativa estratégica básica fundava-se na eficácia dessa embarcação na defesa do imenso litoral do país no Atlântico Sul, por suas características de discrição, autonomia e velocidade. A isso se aliava o argumento existente desde o começo dos anos 1950 de que o Brasil precisava dominar a tecnologia atômica, em um quadro em que os Estados detentores desse conhecimento dificilmente se disporiam a compartilhá-lo com o país.

$\mathrm{Na}$ sua origem, sob o governo do quarto presidente militar, o general Ernesto Geisel, a decisão da Marinha de caminhar no sentido do domínio da tecnologia da propulsão nuclear para submarinos de ataque motivou-se pela rivalidade regional com a Argentina. Posteriormente, a utilidade estratégica do submarino deslocou-se para a visão de que o Brasil precisava dispor de uma arma que dissuadisse aventuras de po-

\footnotetext{
* Artigo recebido em 15 de agosto de 2011 e aprovado para publicação em 12 de dezembro de 2011.

** Doutor em Ciências Sociais pela Universidade Estadual de Campinas (Unicamp) e professor associado do Departamento de Ciências Sociais e Programa de Pós-graduação em Ciência Política da Universidade Federal de São Carlos (UFSCar). E-mail: djrm@ufscar.br.
} 
tências mundiais em sua costa. As recentes descobertas de petróleo na camada do pré-sal fortaleceram a decisão tomada há mais de quatro décadas.

Neste artigo, procuraremos analisar a evolução de um programa que se alongou já por mais de trinta anos, dois regimes políticos e profundas mudanças no cenário internacional, a fim de entender o que levou as diferentes administrações da Marinha e os diversos governos federais a mantê-lo, bem como as dificuldades que o projeto enfrentou desde sua definição e as opiniões que suscitou na força naval. Para tanto, partiremos da ideia de oportunismo tecnológico, segundo a qual as decisões tomadas por um país sobre tecnologias militares não se referem às preferências por um determinado armamento, mas a visões estratégicas mais amplas, que conjunturalmente encontram em um armamento específico canal para sua implementação. Ao estudar essas visões estratégicas, tanto na Marinha como no Executivo, chega-se à conclusão de que as diferenças no apoio ao programa do submarino parecem se relacionar não à diferença entre os regimes políticos, mas a visões diversas quanto ao lugar do país no sistema internacional e à melhor maneira de defender os interesses nacionais. No caso específico da Marinha, há que se considerar também conflitos pessoais e intraburocráticos, além de problemas colocados pelo caráter autárquico e secreto que o programa adquiriu.

\section{Breve História do Programa}

Em 27 de junho de 1975, sob o impacto da crise do petróleo, o Brasil surpreendeu o mundo ao assinar com a República Federal da Alemanha um acordo nuclear que previa a construção até 1985 de dois reatores nucleares para produção de energia no país, tendo como motivação a expectativa de dominar o ciclo do combustível nuclear, especialmente sua etapa mais difícil: o enriquecimento isotópico do urânio. Como lembra um ex-oficial da Marinha e assessor da presidência da Eletronuclear no governo Lula (2003-2010):

Quando da assinatura do Acordo, o País [Brasil] já dominava a etapa inicial do ciclo do combustível - da mineração do urânio até a 


\section{O Projeto do Submarino Nuclear Brasileiro}

produção do "yellow cake" - nas instalações de Poços de Caldas, e o Centro de Engenharia Química do IPEN já dominava, em escala laboratorial, as etapas de purificação e produção de hexafluoreto de urânio. Ainda no IPEN, já havia incursões às etapas de reconversão e produção de pastilhas (GUIMARÃES, 2003, p. 137). ${ }^{1}$

Em maio de 1976, o subsecretário de Pesquisa Tecnológica e Científica da República Federal da Alemanha, Hans-Hilger Haunschild, escreveu a Paulo Nogueira Batista, presidente da Nuclebrás - empresa estatal criada em 1974 para implementar o Programa Nuclear Brasileiro -, para destacar o know-how de seu país no desenvolvimento da propulsão nuclear naval, graças ao projeto iniciado nos anos 1950 e que resultou no navio científico Otto Hahn. ${ }^{*}$ Em 15 de julho de 1976, o ministro brasileiro da Marinha, Geraldo Henning, explicou ao presidente Geisel que sua força estava disposta a pensar no desenvolvimento futuro de propulsão nuclear para navios de guerra, mas que no momento sua participação deveria se restringir à aquisição de conhecimentos (CORRÊA, 2010, p. 59).

Dois dias depois, o presidente da Nuclebrás dirigiu-se ao presidente, comentando a correspondência com os alemães citada acima e aventando a possibilidade de o Brasil vir a construir, a longo prazo, um navio auxiliar da Marinha, possivelmente de pesquisas oceanográficas, com propulsão nuclear. Nogueira Batista referia-se também ao eventual interesse "parcial e não prioritário" da Nuclebrás e da força naval nos projetos alemães nessa área. Para tanto, propunha a criação de um núcleo inicial de trabalho, e concluía: "Sugiro que um ou dois engenheiros navais se agreguem a este núcleo sem perder sua vinculação com a Marinha, para iniciar e motivar suas atividades no campo da propulsão naval nuclear, a cargo da Diretoria de Engenharia Naval.",

\footnotetext{
* O navío Otto Hahn funcionou predominantemente como navio de pesquisa, até ser transformado em navio puramente mercante, sem propulsão nuclear, em 1982. [N. do E.]
} 
No mês seguinte, Murillo de Castro, assessor da presidência da Nuclebrás, encontrou-se com o comandante Armando Vidigal, subchefe de Gabinete do ministro Henning. Vidigal reafirmou que a Marinha do Brasil (MB) tinha interesse no projeto, embora seus recursos fossem limitados. Em seu relatório ao presidente da Nuclebrás, Castro explicou:

Pensou-se em que o primeiro objetivo material poderia ser a instalação de um reator de propulsão nuclear em um dos estabelecimentos ou bases navais que pudesse manter vivo e consubstanciado o interesse pelo assunto e servir de base ao ensino e adestramento dos técnicos e experimentação.

E concluiu: "Nada foi debatido com relação à utilização de reatores em navios mercantes ou militares." Em 14 de setembro, foi feita nova reunião na sede da Nuclebrás, no Rio de Janeiro, da qual participaram Nogueira Batista, Castro, Vidigal e outros. Logo depois, os alemães efetivamente propuseram a cooperação dos dois países em um projeto de propulsão nuclear para um navio mercante. No dia 24 do mesmo mês, o presidente da estatal dirigiu-se ao presidente Geisel para relatar que teria ouvido do diretor da empresa alemã Interatom, que construiu o reator do Otto Hahn, "a hipótese de um trabalho conjunto para a produção no Brasil de submarinos nucleares".

Para Nogueira Batista, "a hipótese de construção de submarinos nucleares no Brasil poderia [...] merecer estudo acurado de nossa parte". Para ele, "o interesse alemão explica-se pelas limitações nesse campo a que está sujeita a RFA em seu próprio território, em consequência dos acordos de Paris de 1954". O ofício terminava com um pedido de autorização a Geisel para que a Nuclebrás pudesse "manter entendimentos com o Ministério da Marinha a respeito do assunto". ${ }^{3}$ Convém destacar que esses movimentos extrapolavam os termos do acordo com a Alemanha, que vetava qualquer emprego militar dos resultados da colaboração entre aquele país e o Brasil. 
$\mathrm{Na}$ carta de Nogueira Batista ao presidente Geisel, o primeiro referiuse a "planos bastante elaborados nesse sentido, que foram objeto inclusive de conversações com a Grã-Bretanha, em passado relativamente recente". Não há mais evidência atualmente sobre esses contatos. Mas, ainda em 1976, em visita ao estaleiro Vickers-Armstrong, em Barrow-in-Furness, na Inglaterra, o diretor-geral do Material da Marinha, almirante Eddy Sampaio Espellet, teria ouvido do presidente dessa firma a sugestão de que a tecnologia dos submarinos de propulsão nuclear da classe Churchill, construídos naqueles estaleiros, poderia servir no futuro ao Brasil. "Não se esqueça de nós", teria dito o executivo. Com efeito, desde pelo menos 1974, a Marinha brasileira registrava o avanço tecnológico representado pela invenção do submarino nuclear e dizia-se que: "Dentro ainda do quadro de obtenção de unidades novas, há dois projetos em estudo destinados a causar grande impacto, a saber: a construção ou aquisição de um porta-helicópteros e a adoção de propulsão nuclear em unidades navais" (ESCOLA SUPERIOR DE GUERRA, 1975, p. 46).

Voltando ao Brasil, o almirante comunicou o fato ao ministro Henning. Em seguida, teria tomado a iniciativa de entrar em contato com o diretor de Engenharia Naval da MB, almirante Nelson Xavier, para sugerir que este conseguisse uma vaga na área de Energia Nuclear do Instituto de Tecnologia do Massachusetts (Massachusetts Institute of Technology [MIT]) e indicasse um oficial para cursar aquela instituição. Segundo a narrativa de Espellet, Xavier disse-lhe em seguida que conseguira a vaga. Foi então escolhido o nome do capitão-tenente Othon Luiz Pinheiro da Silva para cursar o programa nos EUA. O jovem oficial reuniria as qualidades de "liderança, iniciativa e entusiasmo", procuradas pelo almirante, e isso ficou claro em conversa que tiveram. Além disso, ele teria garantido que não pretendia deixar a força. A sugestão teria sido enviada ao ministro da Marinha, que a aprovou, submetendo-a em seguida ao próprio presidente Geisel e obtendo sua concordância (ESPELLET, 2009). ${ }^{4}$

Quando, em 1978, Othon retornou ao Brasil, já com sua pósgraduação em Energia Nuclear, o diretor-geral do Material da Marinha, o almirante Maximiano da Fonseca, o alocou na Diretoria de En- 
genharia Naval (DEN). À mesma época, Maximiano chamou o oficial e lhe indagou quais eram as chances de que se pudesse ter a propulsão nuclear naval no Brasil. Este respondeu que precisaria de três meses para escrever um relatório sobre o assunto, ficando acertado que seu primeiro trimestre na DEN seria dividido entre suas atribuições regulamentares e a redação do texto. ${ }^{5}$ Entregue o relatório, em maio de 1978, Maximiano, "muito impressionado" com este, o encaminhou ao Estado-Maior da Armada (EMA), onde foi atribuído para parecer ao subchefe de Estratégia do EMA, o almirante Mario César Flores, e certamente acompanhado de perto pelo almirante Espellet, chefe do EMA (ESPELLET, 2009).

\section{O projeto Chalana}

O almirante Flores estudou cuidadosamente o relatório, recorrendo a consultas a "várias pessoas da comunidade científica" e chamando a Brasília algumas vezes o próprio autor do documento, antes de emitir parecer favorável à sua aprovação. Em reunião do almirantado realizada entre o Natal e o final do ano de 1978, Flores apresentou seu parecer e foi tomada a decisão de levar adiante o programa do submarino de propulsão nuclear. ${ }^{6} \mathrm{O}$ relatório de Othon continha duas metas principais a serem cumpridas no país para chegar à capacidade de construir um submarino de propulsão nuclear no Brasil: o domínio do ciclo de enriquecimento do combustível nuclear e a construção de um reator piloto para testes. Segundo lembra o almirante Maximiano, essas metas deveriam ser alcançadas "usando unicamente esforço nacional, de forma a evitar qualquer impasse com os tratados e acordos assinados" (CORRÊA, 2010, p. 62). O programa secreto da Marinha recebeu o nome de Chalana e "se desmembrava em dois projetos. O Ciclone, que perseguia o desenvolvimento do ciclo do combustível nuclear, e o projeto Remo, que era o desenvolvimento de propulsão nuclear para submarino". 7 Altamente secreto, o projeto era de conhecimento apenas dos almirantes de esquadra. Com efeito, o almirante Mauro Cesar Rodrigues Pereira esclarece que em 1983 foi nomeado pelo ministro da Marinha para servir na Secretaria Geral do Conselho de Segurança Nacional, "dizendo-me haver lá assunto sigiloso de muita importância para a MB". Ainda assim, ele teria passado vários meses sem conhe- 
cer "o problema, pois era tratado com alto grau de sigilo em outro setor que não o meu". 8

Retomando a narrativa cronológica, naquela altura Othon desenvolvera, com base em conhecimento e informações obtidos em sua estada nos EUA, uma postura bastante crítica com relação ao modelo de enriquecimento fornecido pela Alemanha, baseado na tecnologia de enriquecimento por jato centrífugo, o jet nozzle: "O método que nós tínhamos comprado [...] no acordo Brasil-Alemanha não passava por uma análise técnica um pouco mais rigorosa. Nós tínhamos investido em uma coisa que não tinha sentido". 9 A isso se acrescentavam as rígidas restrições do acordo quanto a qualquer aplicação militar de seus resultados. Diante desse quadro, o engenheiro naval propôs que, para ganhar tempo e para contornar as pressões e restrições internacionais, o programa investisse no método de enriquecimento por laser então em curso no Centro Tecnológico da Aeronáutica (CTA) sob a chefia do coronel José Albano do Amarante, no interior do Programa Nuclear Paralelo criado pelo general Geisel. Se essa tentativa não funcionasse, sugeria "que nós apostássemos na tecnologia da ultracentrífuga, que essa eu tinha certeza de que daria certo". Segundo o almirante Espellet, foi sua a iniciativa de propor ao almirante Maximiano, agora ministro da Marinha do governo Figueiredo, que Othon fosse mandado ao CTA, onde trabalhava o físico Sérgio Mendes, também professor da Universidade Estadual de Campinas: "Perguntei ao brigadeiro Lucena, chefe do Estado-Maior da Aeronáutica, se ele receberia o Othon. Pouco depois ele me deu o afirmativo." Espellet pediu então ao ministro que "fizesse um aviso ao Brigadeiro Araripe, ministro da Aeronáutica, solicitando a transferência" de Othon para aquela unidade da Força Aérea Brasileira (ESPELLET, 2009).

Dessa forma, em março de 1979, Othon foi designado para servir com o tenente-coronel Amarante no CTA. No entanto, a ideia da colaboração não avançou. Pesou para tanto o falecimento de Amarante - acometido por leucemia, após visita aos EUA - e a conclusão do próprio Othon de que o enriquecimento a laser "em um universo de vinte anos não teria resultados práticos". ${ }^{10} \mathrm{Em}$ meados daquele ano, o oficial teria enviado um relatório nesse sentido ao Estado-Maior da Armada, rece- 
bendo sinal verde para contatar as instituições necessárias para viabilizar o projeto da ultracentrifugação (CORRÊA, 2010, p. 75).

Mas a colaboração com o CTA renderia um fruto fundamental: ela possibilitaria o uso pela Marinha de um convênio que o centro mantinha com o Instituto de Pesquisa Energéticas e Nucleares (IPEN) (até 16 de março de 1979, Instituto de Pesquisas Atômicas), da Universidade de São Paulo (USP). Com a cumplicidade de Amarante, e sem consultar o chefe da Comissão Naval em São Paulo, Othon conseguiu assinar um convênio com a Secretaria de Ciência e Tecnologia do Estado de São Paulo, o que possibilitou a contratação de vinte engenheiros e quarenta técnicos para implementar o programa do submarino. Em seguida, com base no argumento de que a Marinha tinha que ficar à altura do apoio do governo de São Paulo, ele foi capaz de convencer o ministro a elevar a equipe que ele chefiava no IPEN para sessenta engenheiros e 120 técnicos, o que exigiu uma autorização direta do presidente Figueiredo. Em fevereiro de 1980, tem início efetivamente o desenvolvimento da primeira ultracentrífuga, concluída em dezembro de 1981. Em agosto de 1982, o programa da Marinha separou-se definitivamente do da Aeronáutica.

Em 4 de setembro de 1982, os experimentos com ultracentrifugação realizados nas instalações da USP levaram a Marinha a anunciar o controle do ciclo de enriquecimento do urânio. Com apenas duas máquinas, alcançou-se o primeiro salto, consubstanciado na passagem "de 711 para um zero alguma coisa", na expressão do próprio Othon. Para ele, "nós, com menos de três anos, tínhamos feito aquilo que a Nuclebrás, gastando um bilhão de dólares, não fez". Em setembro de 1984, o programa contava com nove centrífugas trabalhando em cascata: "A fase de 1982 a 1984 foi para a gente entender o funcionamento coletivo das máquinas", completa o oficial. Nos três anos seguintes, os esforços concentraram-se no programa de "industrialização", dentro do qual foram desenvolvidos todos os componentes necessários para a futura usina de enriquecimento, inclusive a liga leve (maraging).

Nessa altura, as evidências de que o regime militar se aproximava do fim induziram à ideia de colocar o programa da Marinha sob o guar- 
da-chuva de um organismo civil, a Comissão Nacional de Energia Nuclear (CNEN). No clima de abertura política então vigente, o comandante do I Distrito Naval, com jurisdição sobre São Paulo, almirante Luiz Leal Ferreira, defendeu na imprensa o submarino nuclear, embora ressaltando que não era um projeto para curto prazo (ALMIRANTE..., 1983). ${ }^{11}$ Logo em seguida, o próprio ministro da Marinha saiu em defesa do programa, com base nas vantagens operacionais e estratégicas do submarino nuclear (MARINHA..., 1983). ${ }^{12}$ Para Guimarães (2003, p. 139),

[...] o IPEN voltou, em outubro de 1982, à esfera federal, e é atualmente subordinado à CNEN. A Marinha, por sua vez, criou a Coordenadoria para Projetos Especiais - COPESP (que teve sua denominação alterada em 1995 para Centro Tecnológico da Marinha em São Paulo CTMSP), sediada junto ao IPEN, para executar o programa. [...] A colaboração com o IPEN evolui ao longo do tempo, envolvendo os demais institutos de pesquisa da CNEN, como o Centro de Desenvolvimento de Tecnologia Nuclear (CDTN), de Belo Horizonte, e o Instituto de Engenharia $\mathrm{Nu}$ clear (IEN), do Rio de Janeiro.

Enquanto isso, o programa progrediu para a ideia da necessidade de se construir uma usina de enriquecimento, mais do que simples ultracentrífugas. O crônico problema da escassez de verbas na força naval foi resolvido com um artifício: para as necessidades dos experimentos com o enriquecimento do urânio, usaram-se verbas advindas do Conselho de Segurança Nacional (CSN), enquanto a Marinha patrocinava, com o apoio decidido do ministro Maximiano, o projeto dos reatores. A movimentação dessa verba lançou mão de contas secretas, conhecidas em setores restritos pelo codinome Delta (CORRÊA, 2010, p. 93). ${ }^{13} \mathrm{O}$ almirante Mauro afirma que, quando assumiu a chefia do Gabinete da Secretaria Geral do CSN, o projeto recebia apoio desse ór- 
gão, "inclusive vultosas verbas". ${ }^{14}$ Nessa época, foi estabelecido um convênio entre os governos federal e estadual que permitiu que o IPEN passasse a funcionar como instituição híbrida. Segundo o almirante Othon, o governo do estado de São Paulo, ocupado pelo oposicionista Franco Montoro, não colocou obstáculos.

O fim do regime militar, em 1985, com a posse do presidente civil José Sarney (1985-1989) não alterou o apoio ao programa. Diante das denúncias vinculadas pela imprensa sobre o Programa Nuclear Paralelo, o novo ministro da Marinha, almirante Henrique Sabóia, explicou que o governo brasileiro não pretendia nem planejava construir a bomba atômica no país e insistiu que a fabricação da bomba ou de armas nucleares dependia de decisão política do governo, o que exigiria recursos não disponíveis (O BRASIL..., 1986). ${ }^{15}$ Nesse contexto, chegou à imprensa a notícia de que a Marinha pretendia construir um centro de pesquisas no interior de São Paulo para possibilitar a próxima etapa de seu programa. ${ }^{16}$

Com efeito, os laboratórios da Marinha até hoje situados na USP permitiram experimentos enquanto o programa tinha apenas escala de laboratório. O almirante Othon resume assim as fases do programa: "O que é em escala laboratorial é na USP, o que é em escala piloto é em Aramar, e já preparando para aderir ao programa energético do país, em escala industrial, em Resende". Segundo Guimarães (2003, p. 139):

Desde a Segunda Guerra Mundial havia uma convivência muito próxima da Marinha com a comunidade científica e universitária de São Paulo, que se iniciara com os trabalhos no Instituto de Física da Universidade de São Paulo (USP) na área de desenvolvimento de sonares, mas que se ampliara com o convênio com o Instituto de Pesquisas Tecnológicas (IPT), e com a decisão de formar a maior parte dos oficiais engenheiros na Escola Politécnica da USP. Ocor- 
reu, assim, naturalmente uma aproximação entre a Marinha e o IPEN, que se tornaram parceiros no empreendimento. A cooperação foi institucionalizada através de um convênio entre a Diretoria Geral do Material da Marinha (DGMM) e o IPEN.

A usina piloto de enriquecimento e a construção do primeiro reator exigiam instalações próprias. Em maio de 1985, o presidente José Sarney decidiu criar o Centro Experimental da Marinha, em uma área onde se situava o sítio Aramar, no interior de São Paulo, próximo à cidade de Sorocaba (CORRÊA, 2010, p. 108), onde seriam construídas instalações piloto com "tamanho suficiente para atender as necessidades da Marinha". Segundo Othon, "quando foi inaugurado Aramar, em 1988, aquilo já era uma usinazinha de enriquecimento, com todos os componentes fabricados no Brasil".

O local foi escolhido por sua proximidade com São Paulo e Campinas, sedes de duas das maiores universidades do país. Aramar prepararia as condições para a futura produção industrial do combustível e dos reatores de potência do tipo água pressurizada (PWR), que seria feita fora dali, nas instalações das Indústrias Nucleares do Brasil (INB), localizadas em Resende, RJ. O centro foi inaugurado solenemente em 8 de abril de 1988 pelo presidente José Sarney com a presença do presidente argentino, Raul Alfonsín. Foi a forma encontrada pelo governo brasileiro de retribuir o convite que o presidente argentino fizera a seu colega brasileiro para visitar as instalações de enriquecimento de urânio de Pilcaniyeu, em setembro de 2007. Efetivado no começo daquele ano, o convite teria levado o presidente Sarney a apressar a inauguração de Aramar, o que implicou na obrigação de construir os prédios e instalar neles as 48 ultracentrífugas no espaço de um ano. A Constituição brasileira de 1988 estabeleceu que a atividade nuclear do país só poderia ter lugar em suas fronteiras e com propósitos pacíficos, previamente aprovados pelo Congresso Nacional (BITENCOURT; VAZ, 2009, p. 9). 


\section{Mudança de Rota}

A ascensão à Presidência da República de Fernando Collor de Mello, no início de 1990, resultou na diminuição das verbas suplementares do programa do submarino nuclear. Já a escolha do almirante Mario César Flores como ministro da Marinha garantiu a manutenção das verbas da força. ${ }^{17}$ Segundo ele, diante da interrupção das verbas antes garantidas pela Secretaria do CSN, a decisão não foi isenta de tensões na Marinha: "Foi um processo decisório difícil, mas que eu tive que arbitrar, quando foi trazido para o EMA, a de sustentar o projeto unilateralmente pela Marinha, o que representou para a Marinha - é importante registrar isso - uma carga pesada." ${ }^{, 18}$ Em 13 de dezembro, o Brasil e Argentina concordaram em assinar o Acordo de Guadalajara para o Uso Exclusivamente Pacífico da Energia Nuclear, com a criação, em seguida, da Agência Brasileiro-Argentina de Contabilidade e Controle de Materiais (ABACC). Com o impeachment do presidente Collor, no final de 1992, e a posse do vice-presidente, Itamar Franco, foi nomeado para o Ministério da Marinha o almirante Ivan da Silveira Serpa.

Na narrativa do almirante Othon, com essa nomeação o problema sofreu sério abalo: "Ele era contrário, e a prioridade caiu logo depois de 1 para 18. Aí começou a complicação: a parálise do programa e a destruição até de uma parcela dele." Na narrativa do criador do programa nuclear da Marinha, seu último ano e meio na direção do programa "eu confesso que foi de pauleira. Todos os processos, tudo que se podia fazer para complicar a vida foi feito". Segundo Othon, a tensão chegou a tal ponto que ele disse a Serpa: "Ministro, a única chance do Sr. ficar livre de mim é pegar a caneta e ter coragem de me demitir." E continua: "Um mês antes de eu sair, ele abriu 33 sindicâncias. Eu passei em todas."19

A narrativa de Othon é contestada frontalmente pelo almirante Mauro. Para este, ao exercer o cargo de presidente da Comissão Naval em São Paulo (CNSP), a Coordenadoria para Projetos Especiais, responsável pelo programa do submarino, era parte integrante da CNSP, mas até aí seus antecessores na função "não tinham acesso ao projeto e sua administração, por força do sigilo que lhe era atribuído". Conhecedor do 
projeto desde o final de 1983, como vimos, o almirante considerou que tal situação administrativa "era difícil de ser aceita", o que fez ver a seus superiores desde sua posse, "resultando que logo após a COPESP fosse transformada em Organização Militar Independente". Para o almirante, nessa altura, o sigilo do projeto era totalmente desnecessário. $^{20}$

Em 1995, com o início do governo Fernando Henrique Cardoso, o almirante Mauro foi escolhido como novo ministro da Marinha. Apoiador da política de Serpa, assumiu com postura crítica diante do apoio incondicional que o almirante Flores deu ao programa do submarino nuclear. ${ }^{21}$ Segundo sua narrativa, quando comandava em 1991 o $5^{\circ}$ Distrito Naval, foi convocado pelo almirante Serpa: "havia solicitado ao ministro de então, Alte. Flores, a realização daquele encontro, que foi a primeira vez em que número significativo de almirantes e oficiais em posições-chave na estrutura naval tomou conhecimento do projeto." E continua:

Nesse encontro, embora com aprovação unânime ao trabalho e conquistas nas áreas de enriquecimento de urânio, ciclo do combustível e reatores nucleares, houve desaprovação generalizada às ideias aventadas para a construção do submarino, seja por sua concepção ou por sua condução à margem da estrutura normal da Marinha, mormente por quem não tinha vivência em construção naval. ${ }^{22}$

Ainda segundo Mauro, os ataques de Othon a Serpa, por ter supostamente aniquilado o programa nuclear da Marinha, são improcedentes e denotam talvez "represália ao fato de ter sido ele o responsável maior pelo afastamento" de Othon "da condução do projeto, com apoio integral do Almirantado", para o que "havia razões muito fortes, embora a decisão tenha sido tomada com toda a cautela na ocasião em que, por 
força de lei, o depoente terminava o prazo máximo de permanência no serviço ativo, buscando assim não prejudicar o projeto, por todos, inclusive pelo Alte. Serpa, considerado de importância vital para a Marinha”. Finalmente, para Mauro, a afirmação de que na gestão de Serpa o projeto caiu "de prioridade 1 para prioridade 18 " é falsa:

O planejamento orçamentário da Marinha é elaborado no Sistema de Plano Diretor, introduzido pelo Ministro Alte. Silvio Motta em 1963 e, desde então, sempre e muito aprimorado. É formado por projetos numerados que se agrupam em Planos Básicos (PB), um dos quais é o PBW (plano Whiskey, pelo alfabeto fonético naval) relativo a energia e submarino nuclear. Até certa época, as prioridades dos projetos eram consideradas apenas dentro do seu PB. A partir de 1994/1995, passou-se a adotar uma única escala de prioridades para todos os projetos da Marinha. É então que surge o tal número 18.

Segundo ele, inúmeros outros projetos fundamentais para a manutenção básica da força "teriam de vir à frente do submarino nuclear". E pergunta: "Ou seria razoável destruir a Marinha e descurar de suas obrigações mínimas para privilegiar um investimento que, se tivesse total sucesso, só se materializaria em quinze ou vinte anos?"23

$\mathrm{Na}$ época em que estava na Secretaria do Conselho de Segurança, aplicava-se nesse projeto coisa da ordem de R\$ 100 milhões, dos quais a Marinha entrava com uns 20 milhões. Depois começou a Marinha a ter que entrar praticamente sozinha e depois sozinha com esses recursos. Ora, se a Marinha recebia 120 e poucos milhões totais para investimento, ela não podia botar $100 \mathrm{mi}-$ lhões no submarino nuclear. Então, o projeto tinha que ser reduzido na sua velocidade. ${ }^{24}$ 
Na narrativa do almirante Flores:

O almirante Serpa foi excessivamente rigoroso em cortar o que ele chamava de excessiva liberdade do Othon. O Othon, por sua vez, não facilitava muito. Eu, o Sabóia que me antecedeu, o almirante Karan, tínhamos paciência com ele, uma certa condescendência, porque entendíamos que era o preço a pagar para que aquilo avançasse, mas quando o almirante Serpa assumiu o Ministério ele resolveu cortar essas coisas e aí houve um conflito violento entre ele e o Othon, do qual eu não participei, pois não estava mais. Eu sabia indiretamente e, a meu ver, foi prejudicial ao projeto. $^{25}$

O sucessor de Mauro Cesar, o último almirante a ocupar o cargo de ministro da Marinha, Sérgio Chagastelles, manteve a política de seus dois antecessores.

\section{O Renascimento}

A vitória de Luiz Inácio Lula da Silva nas eleições presidenciais do final de 2002 abriria as condições para uma nova valorização do programa do submarino nuclear. Em fins de 2005, a Marinha debatia-se com a falta de recursos e com a possibilidade de que o orçamento de 2006 fosse menor que o de 2005. Seu novo comandante, o almirante Roberto de Guimarães Carvalho, preocupava-se, sobretudo, em estancar o que considerava a degradação do material flutuante, que teria chegado a "níveis considerados críticos" (ENTREVISTA..., [s.d.]). Nesse sentido, ele encaminhou à Casa Civil da Presidência um programa de investimentos para um período de vinte anos, no valor de US\$ 2,57 bilhões, com o fim de superar a deterioração do material flutuante e retomar os projetos estratégicos da força. Surgiu então a proposta de R \$ 130 milhões durante oito anos para retomar o projeto do submarino nuclear, o que possibilitaria construir duas usinas de enriquecimento de urânio e instalações adequadas para o Laboratório de Geração Nucleoelétrica (Labgene) 
(MARINHA..., 2006a). A Marinha anunciou em seguida que completara com sucesso no Labgene, em uma sala improvisada, a montagem do vaso de pressão e componentes internos do protótipo de reator do futuro submarino (MARINHA..., 2006b). Mesmo assim, ainda uma vez, na gestão de Carvalho o projeto perdeu prioridade diante das necessidades mais prementes da força.

Somente no início do segundo governo Lula, no início de 2007, a escolha do almirante Moura Neto para o comando da Marinha recolocou o submarino nuclear como prioridade da força. Na visão do almirante Othon, terminava aí a predominância de quatro administrações da Marinha que tinham resistências ao projeto. Em entrevista concedida ao jornal de esquerda Hora do Povo, publicada em 22 de novembro de 2006, Othon afirmou: "Determinada escola de pensamento - e nós tivemos quatro administrações dessa escola - não quer terminar. [...] $\mathrm{O}$ atual chefe do Estado-Maior da Armada - que espero que entre na compulsória - propôs a parálise do programa".

Sua visão é novamente contestada pelo almirante Mauro. Segundo ele, as administrações da Marinha a que Othon se refere (Serpa, Mauro, Chagastelles e Guimarães Carvalho), "além de serem conscientemente defensoras da necessidade vital de a MB contar com o submarino nuclear, lutaram com as ferramentas de que podiam dispor, cada uma a seu modo, para não deixar o projeto morrer, condenado que estaria se não houvesse imaginação para superar o estrangulamento de recursos com que tiveram que lidar". Ainda conforme o almirante, quando ocorreu a eliminação do financiamento conjunto do projeto pelo CSN, não houve inicialmente "redução significativa dos recursos aplicados, sendo facilmente verificado que foi de 1994 a 1998 que a Marinha aplicou a maior porcentagem dos recursos a ela própria destinados no PBW". Depois disso, veio a redução dos orçamentos das Forças Armadas, segundo Mauro conhecida por todos, "exceto os mal-intencionados".

Na sua própria gestão, o ministro Mauro levou o presidente Fernando Henrique Cardoso a Aramar e visitou a França, onde entabulou negociações com o ministro da Defesa e o comandante da Marinha, com o propósito de receber tecnologia para abreviar o caminho de obtenção 
do submarino nuclear. Tais ações não prosperaram devido à impossibilidade de atender então à exigência francesa de compra simultânea de submarinos convencionais, o que a situação orçamentária da época impedia. Por fim, o ministro Mauro teria conseguido do governo Cardoso a reversão da decisão de utilizar urânio enriquecido importado na fábrica de combustível nuclear de Resende (RJ). Teve sucesso, pois o governo concordou em utilizar para esse fim a produção de Aramar. Para Mauro, em síntese, "durante as quatro administrações citadas, houve necessidade de recolocar a condução do Projeto Nuclear nos moldes de seriedade e cuidados, como é prática na Marinha e que havia sido distorcida, em certos caso de forma grave, em todo o período anterior à reorientação ordenada pelo ministro Serpa". ${ }^{26}$

Voltando ao governo Lula, em 10 de julho de 2007, o presidente da República visitou as instalações de Aramar, na companhia do almirante Othon, que retornava ao local pela primeira vez desde 1994, e na ocasião anunciou ao diretor do programa, almirante Bezerril, que liberaria a verba almejada de 1 bilhão de reais, no espaço de oito anos (GOVERNO..., 2007).

Enquanto isso, a Marinha criava a Coordenadoria Geral do Programa de Desenvolvimento do Submarino Nuclear (COGESN), para a qual foi nomeado o almirante José Alberto Accioly Fragelli, ex-chefe do Estado-Maior da Armada. No início de 2008, o titular da pasta da Defesa, Nelson Jobim, anunciou que iria à França para encontrar-se com o presidente Nicolas Sarkozy, conhecer a base naval de Toulon, visitar um submarino atômico da frota daquele país e manter contato com Jean Poimboeuf, presidente do DCNS, estaleiro que fabricava o submarino Scórpene (JOBIM..., 2008).

Logo depois, o presidente da França, em encontro com Lula, na fronteira da Guiana Francesa com o território brasileiro do Amapá, anunciou que os dois países assinariam ainda naquele ano um amplo acordo na área militar e da defesa e que poderia incluir a construção de um submarino da classe Scórpene em nosso país (FRANÇA..., 2008a). Para o mandatário francês, tratava-se de uma "parceria estratégica" que incluiria o apoio decidido de seu país à aspiração brasileira por um assento permanente no Conselho de Segurança da ONU. 
Em seguida, os presidentes da França e do Brasil assinaram o compromisso de cooperação militar que previa a construção de quatro submarinos diesel-elétricos da classe Scórpene e do casco do submarino que abrigará a propulsão nuclear, a serem fabricados no Brasil, além da construção, na Baía de Sepetiba, litoral do Rio de Janeiro, de uma nova base para a força de submarinos e de um estaleiro a ser operado no Brasil pelo setor privado francês e devolvido ao país em vinte anos (FRANÇA..., 2008b). O almirante Fragelli atribuiu a nova disposição do país "à visão estratégica do presidente Lula e do comandante Júlio de Moura Neto", e disse que, quando o Brasil se tornar o sexto país do mundo a dispor de um submarino nuclear, "será muito maior do que é hoje como nação, do ponto de vista militar e estratégico" (SUBMARINO..., 2009a). Para o almirante Othon: "O presidente Lula tem uma visão estratégica. É uma coisa impressionante." ${ }^{27}$

Em fins de março de 2010, a Marinha anunciou que se preparava para começar os testes de uma usina para produção do gás hexafluoreto de urânio (UF-6), fechando o domínio do ciclo nuclear (BRASIL..., 2010). O custo oficial do projeto dos submarinos, a ser basicamente financiado pelo banco francês BNP Paribas, seria de 6,8 bilhões de euros, dos quais 2 bilhões de euros apenas com a construção do casco do primeiro submarino nuclear (SUBMARINO..., 2009b; BRASIL..., 2009). Em visita às instalações de Iperó, no segundo semestre de 2010, este pesquisador pôde constatar que o local se tornara um canteiro de obras.

No entanto, dados os imensos investimentos exigidos pelo projeto, seu próprio sucesso no passado recente desperta incertezas quanto ao futuro. Em depoimento ao autor deste artigo, gravado poucos meses antes de seu falecimento, em 14 de dezembro de 2009, o almirante Vidigal externou suas dúvidas nas palavras seguintes:

O submarino nuclear transformou-se em um símbolo para a Marinha. Nosso objetivo supremo é o submarino nuclear. E eu tenho medo de que isso não seja saudável para a Marinha. Do mesmo modo de que no passado nós nos fixa- 
mos na guerra antissubmarino, como a solução de todos os problemas navais, e deixamos de enxergar outras coisas que podiam estar acontecendo, eu tenho medo de que o submarino nuclear possa ter esse mesmo papel no futuro. Acima de tudo, por causa do custo extraordinário dele, não só para construir o submarino, o que já é uma despesa fantástica, mas vai ser preciso construir uma base própria para o submarino nuclear. Uma base capacitada para fazer todos os reparos, toda a manutenção para o submarino nuclear. Vamos ter que ter um estaleiro com uma competência extraordinária no sentido de construir esse submarino. Então, ao preço da construção do submarino, vamos ter que somar o preço da construção de uma base futura para ele, com um estaleiro capaz de construí-lo. Tenho eu o receio de que, se nós nos direcionarmos somente nesse sentido, outras coisas deixarão de ser feitas. Será que nós temos recursos para olhar a área de mísseis, que cada vez tem um papel mais relevante na guerra no mar? Será que nós vamos ter capacidade para desenvolver o nosso próprio navio-aeródromo, com aviação, se possível, nacional? Ou será que todos os recursos da Marinha vão ficar concentrados nessa única direção? Aí, o submarino nuclear pode ser uma ameaça à Marinha. Eu digo com muito receio porque a Marinha transformou o submarino nuclear em um símbolo, e quem for contra esse símbolo vai encontrar uma séria oposição na Marinha. 


\section{Marinha, Tecnologia e Política}

O programa do submarino nuclear oferece condições privilegiadas por sua duração e complexidade - para avançar na compreensão das relações entre processos decisórios militares e políticas de governo. No exame dessas relações entre tecnologia militar e política, recorreremos ao conceito de oportunismo tecnológico. Esse conceito parte da percepção de que as doutrinas e estratégias militares respondem mais a orientações militares e a percepções dos estadistas sobre a política internacional do que à natureza em si das tecnologias dos armamentos. Nesse quadro, "as elites políticas e militares não tendem a moldar suas estratégias com base na tecnologia militar, mas em vez disso a ver a utilidade de novas tecnologias através das lentes de suas estratégias correntes" (LIEBER, 2005, p. 153). Em outras palavras, os políticos e os estrategistas pensam, em geral, em como uma dada tecnologia pode ajudar sua própria estratégia, não como uma dada tecnologia pode mudar sua estratégia. É a visão do cenário internacional por parte dos líderes políticos e dos estrategistas militares o que pesa - e não a adesão a um programa tecnológico militar específico.

Para Lieber (2005, p. 157), "os Estados raramente veem os novos desenvolvimentos tecnológicos como um meio para preservar o status quo ou sinalizar intenções benignas, mas, ao contrário", apropriam-se de tecnologias, mesmo aquelas apresentadas como defensivas, enquanto oportunidades potenciais para ganhar vantagens militares e políticas no cenário internacional. O oportunismo tecnológico explicaria melhor que outros conceitos as razões das posturas de apoio ou antipatia diante de determinado projeto militar. Além disso, ajudaria a compreender porque, mesmo com o risco de enfrentar desconfianças no cenário internacional, os Estados ousam apresentar projetos tecnológicos de grande impacto. Em suma, não é a predileção pelo projeto do submarino nuclear em si, nem a adesão a uma visão defensiva ou ofensiva do papel desse submarino, o que leva militares e políticos a apoiar o projeto da Marinha; chega-se a esse apoio por motivos relacionados a visões sobre as relações de força internacionais.

Eventualmente, o apoio conjuntural a um projeto pode por certo responder a outro tipo de oportunismo, aquele que se relaciona a necessi- 
dades transitórias da política doméstica. Contudo, são as visões voltadas para relações internacionais o fator fundamental. O projeto tecnológico não é assim um fetiche, mas um meio para alcançar determinados fins, que resultam de percepções sobre os interesses nacionais. No caso que nos interessa, tudo indica que as coalizões político-militares nacionalistas tenderam a apoiar com mais vigor o projeto do submarino nuclear do que as coalizões "internacionalistas", ou, para usar um termo corrente, "neoliberais". Isso se deu independentemente do regime político ou da ideologia dominante. Mas resta entender como as relações de forças dos componentes dessas coalizões variam com o tempo e influenciam de forma diversa o processo de decisões. Esse será o objetivo da análise seguinte.

\section{As Relações de Força na Marinha}

Nossa narrativa anterior trouxe à luz as tensões que ocorreram na Marinha em torno do programa aqui examinado. Em certa medida, essas divergências podem ser atribuídas a posturas defensivas dentro da corporação, resultantes de disputa por parcelas do orçamento e pessoal. Um exemplo disso são os atritos dos encarregados do programa do submarino nuclear com o pessoal da Diretoria de Material da Marinha. Para Othon, "a área de engenharia da Marinha era muito contra. Teve um momento em que os três almirantes engenheiros eram contra. E era explicável, porque a gente começou a tirar recursos humanos da outra parte e isso gerava atritos internos". ${ }^{28} \mathrm{Na}$ literatura da ciência política, essas tensões poderiam ser vistas como o choque entre dois modelos de processos decisórios. O primeiro, conhecido como racional, seria fundado em argumentos modernizantes e de interesse comum. $\mathrm{O}$ segundo, chamado de incremental, está mais preso a considerações corporativas, preocupando-se em manter a estrutura da força e os gastos com pessoal (DAGNINO, 2010, p. 123). Outras fontes de tensão podem ser localizadas no caráter autárquico e de alto segredo do programa. Por fim, mas não menos importante, é preciso mencionar os conflitos de personalidades.

Restaria examinar se as tensões no interior da força naval se vinculam a diferentes visões estratégicas. Nesse sentido, é bom lembrar que, no 
processo decisório da Marinha, ideias surgidas no setor de Engenharia prosperam apenas se obtiverem apoio de setores que podem ser minoritários, desde que tenham postos-chave de comando. De modo geral, o que ocorre é que coincidem proposições técnicas com visões estratégicas. No caso do submarino nuclear brasileiro, o marco decisivo foi a decisão tomada em novembro de 1978 no âmbito do Estado-Maior da Armada. O relato que apresentamos acima deixa claro o papel que tiveram alguns altos oficiais nesse processo, especialmente os almirantes Flores, Vidigal e Maximiano.

Nesse sentido, é bom lembrar que, em março de 1976, Flores e Vidigal tinham publicado um pequeno livro, classificado como "confidencial", com o título de Desenvolvimento naval brasileiro - tópicos para debate, que constituía uma espécie de tradução para a teoria estratégica naval da estratégia política do presidente Ernesto Geisel (1974-1979), que procurava explorar ao máximo os espaços de autonomia do país no cenário bipolar da Guerra Fria, principalmente em relação aos Estados Unidos: “Acreditamos que nos convém aliviar as concepções estratégicas básicas que orientam o preparo do poder militar brasileiro de sua excessiva vinculação à estratégia americana, que nos subordina aos interesses estratégicos dos EUA em seu confronto com a URSS" - diziam os dois oficiais (VIDIGAL; FLORES, 1976, p. 47).

Nesse quadro, eles propunham que a Marinha abandonasse a perspectiva estratégica do papel auxiliar do Brasil na defesa do Atlântico Sul, baseada na hipótese de um conflito generalizado entre as duas superpotências, e passasse a pensar em seus próprios interesses. Em nossa visão, a conjunção dessas visões estratégicas com a oportunidade tecnológica propiciada pelas ideias do comandante Othon explica o lançamento do programa do submarino nuclear. Quando indagado por este pesquisador sobre a provável relação entre as ideias expostas no livro e o começo do programa que ele coordenou, Othon respondeu:

Foi exatamente o que ocorreu. Havia algumas pessoas que tinham pensamento estratégico. A capacidade de uma só pessoa é muito limitada. Ou existe um pensamento ou as coisas não 
saem. Existia um pensamento embrionário, que era minoritário, mas era muito forte. Esse era o cenário. Até hoje é assim. A cultura do conflito bilateral, não mais a cultura, mas o costume, permanece. Naquela época, havia a cultura e o costume. A propulsão nuclear era vista como uma abstração científica pela maior parte. Mas tinha um grupo que não, que achava que realmente era necessário.

Embora no livro citado acima a autonomia estratégica naval fosse pensada em termos de navios de superfície, ainda sob o impacto da aquisição das fragatas britânicas, o relatório redigido pelo almirante Othon possibilitou que capturassem a oportunidade, vendo no submarino nuclear um caminho para o futuro. Para usar as palavras do próprio criador do programa, os adeptos da mudança de visão estratégica viram-se diante de um projeto que, embora temerário, era concreto e viável e "apontava início, meio e fim". No governo Geisel, completou esse quadro a presença do almirante Henning no Ministério (tendo Armando Vidigal na chefia do Gabinete) e do almirante Maximiano na Diretoria de Materiais. No governo Figueiredo, a força do grupo expressou-se na própria ascensão de Maximiano a ministro. Essa coalizão teve continuidade com os almirantes Karam e, já no governo civil, Sabóia.

Quando chegou ao Ministério, já no quadro do pós-Guerra Fria, o almirante Flores era um entusiasta radical do programa. Com efeito, no livro Bases para uma política militar, Flores via o submarino como o eixo da defesa distante da costa brasileira: "Hoje em dia parece mais razoável que, para ser útil à dissuasão de pressões militares e de aventuras regionais, o preparo naval deva ser direcionado para a defesa distante (inquietação do fator ameaça)" (FLORES, 1992, p. 133). A continuidade com as ideias do autor de meados dos anos 1970 parece estar aqui na noção de "pressões militares", uma espécie de senha para se referir discretamente à eficácia do submarino contra pressões das grandes potências, principalmente os Estados Unidos. Mais recentemente, como vimos, esse conceito evoluiria para a ideia de negação do mar. 
A fase mais problemática para a verificação da hipótese é o período pós-Guerra Fria. A manutenção de clivagens dentro da Marinha que remetem ao contexto bipolar, proposta pelo almirante Othon, é negada frontalmente pelo almirante Mauro, para quem essa versão é espúria e se relacionaria aos oficiais mais próximos ao projeto ou a supostos especialistas navais em estratégia, "sem embasamento na prática dos exercícios no mar e na esquadra", que influenciaram a visão civil sobre a Marinha. O ex-ministro da Marinha nega inclusive a pertinência da importância de considerar os períodos da Guerra Fria e do pós-Guerra Fria como fases diferentes para analisar as tensões em torno do projeto do submarino nuclear em termos de visões estratégicas distintas:

Esse embate de opiniões existiu nas discussões da década de 1960, mas estava absolutamente superado nos anos 1970. Bem antes do término da Guerra Fria e não por causa de sua extinção, o pensamento naval brasileiro já considerava a necessidade de traçarmos nossos rumos por considerações estratégicas próprias. ${ }^{29}$

De nossa perspectiva, a distinção entre os dois períodos se mantém, mas é preciso reconhecer três complicadores que se colocam ao entendimento da conjuntura do pós-1989. Em primeiro lugar, no Brasil, a mudança da conjuntura estratégica internacional coincidiu com as políticas neoliberais de contenção orçamentária. Em segundo, há evidências de que pelo menos nas gestões dos almirantes Mauro e Guimarães Carvalho houve medidas destinadas a preservar o projeto, que resultaram infrutíferas em razão da conjuntura econômica acima. E, por fim, parece inegável que é forte na Marinha a visão do submarino nuclear como arma de prestígio, como lembrou o almirante Vidigal no depoimento citado antes. Assim, no estágio atual da pesquisa, diante da escassez de documentos, somente novas entrevistas poderão nos fazer avançar na compreensão do quadro interno à Marinha. O Gráfico 1, abaixo, fornecido pelo Comando da Marinha, permite verificar a flutuação dos gastos no Programa Nuclear da Marinha (PNM): $:^{30}$ 


\section{Gráfico 1}

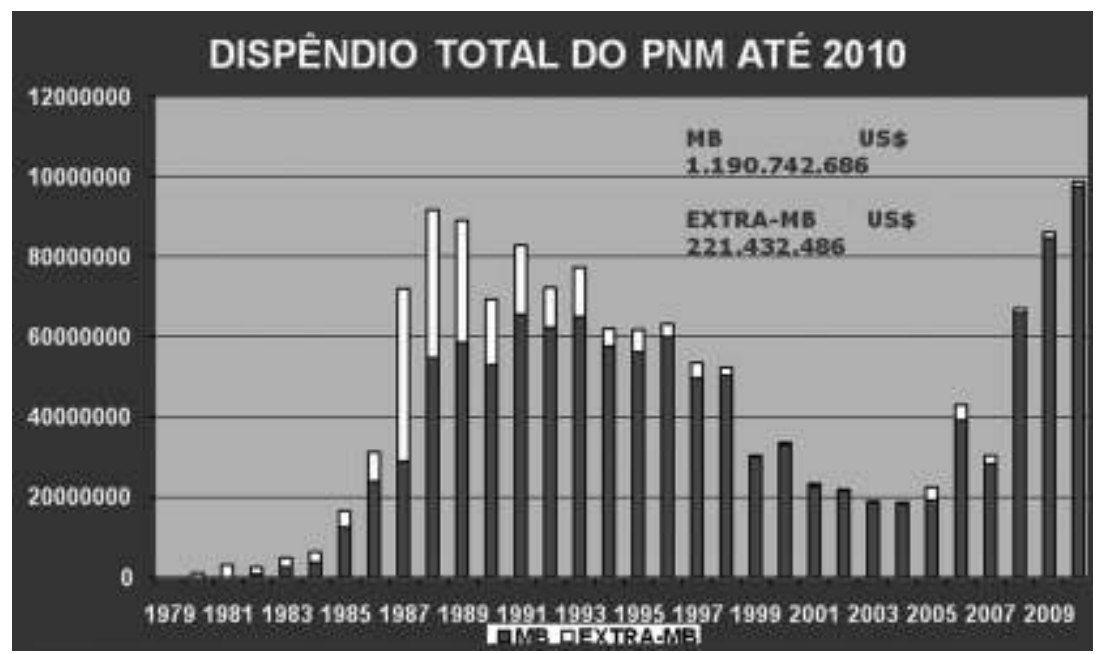

\section{A Política e o Submarino}

$\mathrm{O}$ argumento do oportunismo tecnológico aparece com mais clareza quando se analisa a atitude dos sucessivos governos brasileiros diante do programa da Marinha. Nossa hipótese é de que os sete presidentes da República aqui considerados se posicionaram sobre a questão a partir de suas visões de política internacional e, em alguns casos, de necessidades de política doméstica. A partir da criação do Ministério da Defesa, em 1999, abre-se a possibilidade de introdução de outro ator político decisivo, mas esse fator demorou a sentir sua presença, dada a fragilidade e transitoriedade que marcaram as gestões dos cinco primeiros titulares da pasta (MARTINS FILHO, 2010).

No que diz respeito ao primeiro dos governos da série, em 1974, no início da administração Geisel, o ministro das Relações Exteriores Azeredo da Silveira ofereceu ao general Ernesto Geisel uma avaliação ousada das perspectivas internacionais que se abriam ao país em plena Guerra Fria. Nessa visão,

[...] o sistema internacional não era mais um ambiente de limitações intransponíveis; havia oportunidades - limitadas, mas reais. Caso a di- 
plomacia brasileira realizasse algumas operações conscientes para "furar as cascas" do sistema internacional, então este cederia às pressões brasileiras (SPEKTOR, 2009, p. 75).

A partir daí, presidente e chanceler lançaram a política do "pragmatismo ecumênico e responsável", cujo argumento explícito era, segundo Matias Spektor (2009, p. 76), "que as prioridades internacionais do país, em seguida ao Golpe de 1964, eram excessivamente estreitas para o mundo de 1974 e chegara a hora de guiar-se mais firmemente pelo 'interesse nacional"'.

O corolário dessa visão era que a Guerra Fria não era mais o critério exclusivo da política entre as nações; as relações Norte-Sul assumiam nova importância (SPEKTOR, 2009, p. 90). Foi esse o quadro que permitiu o Acordo Nuclear Brasil-Alemanha, resultado da crença do general e de seu ministro das Relações Exteriores na autonomia como valor da política externa. Como destacou Spektor (2009, p. 125), "para eles, o nacionalismo era um - se não o mais - importante instrumento para fortalecer o país, enriquecer a nação, projetar a influência brasileira no mundo, resistir às pressões hegemônicas dos Estados Unidos e defender o regime". É preciso entender, nesse quadro, o apoio de Geisel às tratativas iniciais relativas à questão da propulsão nuclear naval e às propostas do comandante Othon quanto à possibilidade do Brasil dominar as tecnologias de enriquecimento e do reator. Apesar da narrativa de Othon, tudo indica que o presidente aprovou pessoalmente a ida desse oficial ao MIT, que teve pouco de aleatória.

O governo do general Figueiredo (1979-1985), embora enfrentando uma situação internacional adversa - segundo choque petrolífero, crise da dívida externa dos países do Terceiro Mundo e advento da Segunda Guerra Fria, sob o impulso da política de Ronald Reagan -, não mudou a orientação geral de nossa política externa (VIZENTINI, 2006, p. 154-156). Ao contrário, a Guerra das Malvinas consolidou as desconfianças brasileiras sobre as intenções das potências mundiais. Sintoma disso, na área militar, foi a frieza com que foi recebida a iniciativa dos EUA de reatar os laços militares rompidos com a denúncia 
do acordo bilateral de 1952 (CERVO; BUENO, 2010, p. 440). No governo Figueiredo, ganha força o Programa Nuclear Paralelo; o CSN garante, como vimos, verbas próprias (e secretas) para a pesquisa de enriquecimento do urânio; e a CNEN, sob a direção de Rex Nazaré Alves, apoia o programa da Marinha. Nesse quadro geral, embora o próprio almirante Othon insista na ausência de relação entre a Guerra das Malvinas e o programa nuclear da Marinha, tudo indica que depois desse conflito o governo militar aguçou a percepção sobre a oportunidade oferecida pelo submarino nuclear de fortalecer, no futuro, nossa defesa marítima contra ações das grandes potências.

A mudança de regime não alterou os termos da equação. $O$ governo José Sarney nomeou para a recém-criada pasta da Ciência e Tecnologia o nacionalista Renato Archer. $\mathrm{O}$ novo presidente e o governador oposicionista de São Paulo, André Franco Montoro, concordaram com a construção do Centro de Aramar, em 1985. Mas foi na política externa, mais uma vez, que surgiram as razões para fortalecer o programa. Em sua estratégia de aproximação com a Argentina, Sarney viu na rápida inauguração do Laboratório de Enriquecimento Isotópico (LEI), primeira etapa da Usina de Demonstração de Enriquecimento Isotópico de Urânio, a oportunidade para retribuir o convite que recebeu do presidente Alfonsín, para visitar as instalações nucleares de Pilcaniyeu. Dessa maneira, as injunções da política externa puseram o almirante Othon diante do desafio de completar o laboratório pioneiro de Aramar em tempo recorde:

E, quando chegou 17 de janeiro de 1987, eu me lembro bem dessa data, o general Bayma me chamou em Brasília e me disse: "Othon, o presidente Sarney foi convidado para ir em setembro a Pilcaniyeu, onde os argentinos enriquecem o urânio, é o centro de pesquisa deles e o presidente Sarney gostaria de fazer um convite a uma coisa da mesma estatura, e nós achamos que a única coisa que pode ter a mesma estatura é aquilo que você está propondo, fazer um usi- 
nazinha de enriquecimento. E a pergunta é a seguinte: você tem praticamente um ano, dá para fazer?"31

No final dos anos 1980, as situações externa e interna começam a mudar e, de novo, o programa perde atrativo. No plano internacional, ressurge a perspectiva de uma détente entre EUA e URSS; no plano interno, a Constituição de 1988 define-se como antibelicista e crítica da corrida atômica. Mas a mudança realmente crucial se deu com a ascensão de Fernando Collor de Mello à Presidência. Com uma política externa voltada para uma maior inserção no cenário internacional por meio da adoção das agendas dominantes nos países centrais, o novo presidente vê na crítica aos programas militares, consubstanciada em lances de propaganda como o fechamento do poço de testes da Serra do Cachimbo, uma oportunidade de diferenciar-se do passado. Funciona aí, em nossa hipótese, uma espécie de oportunismo tecnológico às avessas. Em abril de 1990, em seus depoimentos para a Comissão Parlamentar de Inquérito que investigava o Programa Nuclear Paralelo, Renato Archer e o almirante Othon criticam as pressões dos Estados Unidos e defendem a independência tecnológica nuclear (CORRÊA, 2010, p. 134). Mas nessa altura já eram profetas desarmados. Para Collor, Aramar representava o passado.

Nos anos 1990,

[...] a política exterior do Brasil desqualificou a força como meio de ação, em favor da persuasão. O país abandonou a tendência iniciada nos anos 1970, em termos políticos, com a transição da segurança coletiva para a nacional e, em termos industriais, com a produção de meios de defesa e dissuasão. Reforçou seu pacifismo, firmando os pactos internacionais de desarmamento (CERVO; BUENO, 2010, p. 469).

Nesse quadro, o almirante Flores afirma que o projeto do submarino “entrou em um processo de congelamento, não foi extinto, mas não 


\section{O Projeto do Submarino Nuclear Brasileiro}

avançava". Para ele, isso durou "todo o governo de Fernando Henrique Cardoso, que eu tenho certeza - eu estive muitas vezes com ele (ele foi ministro da Fazenda quando eu era secretário de Assuntos Estratégicos) - nunca manifestou nenhum entusiasmo pelo projeto". ${ }^{32}$

Após o impeachment de Collor, o governo Itamar Franco promoveu certa reaproximação com os militares, mas a política externa dos chanceleres Fernando Henrique Cardoso e Celso Lafer manteve os rumos definidos no governo anterior. Em 18 de novembro de 1998, o chanceler Felipe Lampreia assinou finalmente o Tratado de Não Proliferação de Armas Nucleares (TNP), removendo um motivo de tensão nas relações externas, principalmente com os Estados Unidos. Na nova conjuntura, o número de funcionários em Iperó, que chegara a oitocentos no apogeu do programa, caiu para a metade (GOVERNO..., 2007).

No final do governo Cardoso, podiam-se perceber mudanças na orientação da política externa. Para dois analistas,

[...] o ataque de 11 de setembro de 2001 e as dificuldades advindas da Rodada Doha da OMC foram choques externos que colaboraram para a alteração da política exterior brasileira, modificando em alguns pontos o curso final do governo FHC, adiantando elementos de mudança que só ficariam mais claros na administração Lula da Silva (VIGEVANI; CEPALUNI, 2007, p. 280).

De todo modo, por motivos de política doméstica, em fevereiro de 2000 o governo federal já anunciara que destinaria $\mathrm{R} \$ 34,7$ milhões para o programa, no rastro da crise energética do ano anterior, que provocou um apagão de eletricidade de graves proporções (CORRÊA, 2010 , p. 162). A verba liberada foi dividida em quatro rubricas, sendo cerca de metade do total destinada à construção do protótipo do reator nuclear; um quarto para infraestrutura e construção do protótipo do submarino; e a parcela restante para desenvolvimento e aplicação da tecnologia nuclear "em pesquisa e empreendimentos". Na época, a 
imprensa anunciou que o reator de 11 megawatts já tinha seus componentes adquiridos, mas ainda não montados (PROJETO..., 2000).

Com a vitória de Luiz Inácio Lula da Silva nas eleições presidenciais do final de 2002, sobe ao poder uma coalizão política mais disposta a explorar as potencialidades do país no quadro internacional, em uma estratégia que alguns analistas chamaram de estratégia da autonomia pela "diversificação", em contraposição ao "distanciamento" do governo Geisel e da "participação" dos governos dos anos 1990 (VIGEVANI; CEPALUNI, 2010). Nesse quadro, antes mesmo da posse, uma das figuras mais importantes do Partido dos Trabalhadores, o deputado federal José Genoíno, defendeu que no novo governo as Forças Armadas seriam reequipadas e o projeto do submarino nuclear ganharia novamente prioridade (PETISTA..., 2002).

Em seguida, surgiram sinais de retomada da política nuclear. O almirante Othon foi retirado do ostracismo e nomeado diretor da Eletronuclear. Entre 2003 e 2004, o governo brasileiro confrontou a Agência Internacional de Energia Atômica (AIEA), quando o Centro Tecnológico da Marinha em São Paulo, responsável pelo programa do submarino nuclear, decidiu ocultar com painéis o conjunto de centrífugas, permitindo apenas a medição do urânio que entra no sistema e do material enriquecido extraído (LULA..., 2007). Ao mesmo tempo, Lula recusou-se a assinar o Protocolo Adicional ao TNP, criado em 1997, que possibilitaria a ampliação da capacidade de fiscalização da AIEA das instalações nucleares brasileiras. Em fins de 2008, a Estratégia Nacional de Defesa (END, Decreto n. 6703 de 18 de dezembro de 2008) deu expressão mais concreta a essas tendências, ao colocar entre suas diretrizes o fortalecimento de três setores de importância estratégica - o espacial, o cibernético e o nuclear.

Nesse quadro, definiu-se o projeto de submarino nuclear como prioridade nacional e como iniciativa que exigiria independência tecnológica. Ao mencionar a hierarquia dos objetivos estratégicos e táticos da Marinha, a END defendeu que, "para assegurar o objetivo de negação de uso do mar, o Brasil contará com força submarina de envergadura composta de submarinos convencionais e de submarinos de propulsão nuclear". Prometia ainda que o país iria acelerar "os investimentos e 
as parcerias necessárias para executar o projeto do submarino de propulsão nuclear". Dizia também que "a Marinha acelerará o trabalho de construção de suas bases de submarinos, convencionais e de propulsão nuclear", e assegurava "completar, no que diz respeito aos programas de submarino nuclear, a nacionalização e o desenvolvimento em escala industrial do ciclo do combustível (inclusive a gaseificação e o enriquecimento) e da tecnologia da construção de reatores, para uso exclusivo do Brasil".

Finalmente, o acordo assinado entre Brasil e França na mesma época deu destaque à compra de quatro submarinos convencionais da classe Scórpene (FRANÇA..., 2008b). O programa do submarino nuclear inseriu-se assim no novo quadro estratégico esboçado nos últimos anos do governo Lula, em que se radicalizou a política externa, com ações como a condenação ao golpe de Honduras e a aproximação com o Irã. O contexto mais amplo dessas ações foi o sucesso do país na superação da crise econômica mundial de 2008 e a descoberta das reservas de petróleo do pré-sal. Segundo alguns estudiosos:

Fica claro que esses dois novos itens colocam o Brasil dentro de um contexto estratégico distinto. Embora esses feitos sejam ainda notícias novas que reverberam em toda a arena internacional, é fácil antecipar que irão criar consideráveis demandas e, assim, pressões, para definições mais ousadas diante da segurança e da defesa. [...] As descobertas de petróleo aumentarão as pressões por "capacidades de defesa" proporcionais à vulnerabilidade dos novos espaços estratégicos (BITENCOURT; VAZ, 2009, p. 29).

\section{Considerações Finais}

Procuramos neste artigo explorar a ideia de "oportunismo ideológico", que nega a hipótese corrente na teoria das Relações Internacionais, segundo a qual a escolha de armamentos defensivos ou ofensivos é de- 
terminante para explicar as tensões nas relações entre as potências. Ao contrário, defendemos aqui que os políticos e os militares não aderem a um novo armamento ou a uma nova tecnologia em virtude de suas características intrínsecas, mas em decorrência de uma visão prévia das relações internacionais, a partir da qual um determinado armamento ou tecnologia são vistos como importantes. No caso do programa do submarino nuclear, os governos militares de Geisel e Figueiredo e os governos civis de Sarney e Lula foram favoráveis ao projeto, a partir de uma visão específica da política externa. Já os governos Collor, Itamar Franco e Fernando Henrique Cardoso se posicionaram contrariamente à ideia, embora não tomassem a iniciativa de cancelar o projeto.

No plano interno da Marinha, a hipótese do oportunismo tecnológico também parece se sustentar, uma vez que foi a partir de uma nova visão estratégica naval que, no final dos anos 1970, importantes oficiais viram o projeto apresentado pelo almirante Othon como útil e relevante. Por outro lado, o artigo procurou mostrar as tensões que ocorreram no interior da força, dado o caráter secreto e autárquico do projeto em tela. Essas tensões opuseram almirantes de influência, mas aparentemente o corte de verbas não dependeu da força, mas de circunstâncias políticas externas. Como ocorre em todas as marinhas, as versões oficiais tentam esconder essas tensões, preferindo passar em público uma imagem de força naval unida e coesa. Como qualquer outra comunidade humana, porém, a Marinha também é palco de choques de personalidades e divergências agudas de opinião.

\section{Notas}

1 Salvo referência contrária, as informações técnicas constantes neste artigo foram retiradas desse autor.

2 Para informações e fontes citadas a seguir, ver CPDOC (FGV), Arquivo Paulo Nogueira Batista, PNB pn n1976.05.26; 26/05/1976 a 28/08/1978. 


\section{O Projeto do Submarino Nuclear Brasileiro}

3 Em 23 de agosto de 1978, o diretor da Interatom ainda escrevia ao presidente da Nuclebrás manifestando seu interesse em avançar a colaboração mencionada acima, referindo-se apenas ao Otto Hahn. O almirante Othon Luiz Pinheiro da Silva, considerado o criador do projeto do submarino nuclear brasileiro, duvida dessas informações. Para ele, a Alemanha não poderia fornecer ao Brasil uma tecnologia que não tinha, uma vez que dominava apenas a propulsão nuclear para navios civis e de superfície. (Depoimento ao autor em 14 de fevereiro de 2011). Contudo, a documentação disponível no CPDOC não deixa dúvida sobre este ponto. Othon também não considera a possibilidade de que a Marinha viesse pensando na propulsão nuclear já antes do acordo com a Alemanha.

$4 \mathrm{O}$ almirante Othon nega a narrativa acima, afirmando que sua ida ao MIT foi resultado de iniciativa própria e a autorização para a viagem foi fortuita: "Não foi uma seleção, como as pessoas disseram." (Depoimento ao autor em 14 de fevereiro de 2011).

5 Sigo aqui a narrativa do almirante Othon. Corrêa $(2010$, p. 62) defende que a origem do relatório foi uma ordem da Diretoria de Engenharia Naval, depois que o almirante Maximiano designou Othon para a DEN. As informações seguintes, inclusive as citações entre aspas, referem-se ao depoimento de Othon ao autor em fevereiro de 2011, a menos que indicado o contrário.

6 Depoimento do almirante Mário César Flores ao autor em 5 de setembro de 2011. Para o almirante Othon, a reunião teria ocorrido em novembro. Segundo ele: "Foi uma decisão de alto nível, porque o vice-chefe do Estado-Maior da $\mathrm{Ar}$ mada, o almirante Ricarti, me levou ao chefe do Estado-Maior da Armada na época, o almirante Auto, e na frente dele me disse: 'Meu filho, você está indo para uma das missões mais importantes que um oficial da Marinha já teve: Deus te ilumine!" (Depoimento ao autor em 14 de fevereiro de 2011).

7 Ver Entrevista... ([s.d.]).

8 Resposta a questionário enviado pelo autor em agosto de 2011.

9 "Em 1977, o Acordo Nuclear Brasil-Alemanha tinha duas facetas. A faceta das centrais e a faceta do ciclo do combustível. As centrais, em geral, eram de muito boa qualidade. Porém, no que diz respeito ao ciclo do combustível, o Brasil quis comprar a tecnologia certa, que lhe foi negada por pressão dos norte-americanos. Em razão disso, os alemães ofereceram outra tecnologia, chamada jato-centrífuga, cuja concepção ainda era muito embrionária, praticamente pré-laboratorial. O Brasil comprou esta tecnologia". (Resposta a questionário enviado pelo autor em agosto de 2011). 
10 Para o general José Carlos Albano do Amarante, em conversa com o autor em 8 de agosto de 2011, a origem da doença foi o contato com material nuclear, para ele intencionalmente criminoso.

11 Disponível em: <http://www.arqanalagoa.ufscar.br/pdf/recortes/R00486.pdf>. Acesso em: mar. 2012.

12 Disponível em: <http://www.arqanalagoa.ufscar.br/pdf/recortes/R00489.pdf>. Acesso em: mar. 2012.

13 Embora logo depois da Guerra das Malvinas uma exposição de motivos do CSN defendesse o apoio mais incisivo ao projeto, Othon nega que houvesse relação entre aquele conflito e o programa. Para a Exposição de Motivos n.0080/82 do CSN, ver Corrêa (2010, p. 87).

14 Respostas dadas ao autor.

15 Disponível em: <http://www.arqanalagoa.ufscar.br/pdf/recortes/R00510.pdf>. Acesso em: mar. 2012.

16 Ver Marinha... (1986a), Marinha... (1986b) e Sabóia... (1986).

17 Em depoimento ao autor em setembro de 2011, o ex-ministro afirmou: "Tive influência para impedir que o projeto caísse no ostracismo completo. O presidente Collor decididamente não era simpático ao projeto, tinha lá suas razões políticas, de política externa. Nunca se manifestou a mim peremptoriamente contrário, mas nunca se manifestou entusiasmado." Apesar disso, em 31 de maio de 1991, o almirante Flores conseguiu levar o presidente a uma visita oficial a Aramar (CORRÊA, 2010, p. 133).

18 Depoimento ao autor em setembro de 2011.

19 Depoimento, já citado, ao autor.

20 Respostas dadas ao autor.

21 "Ele é que deu toda a cobertura às coisas que o Othon começou a fazer de errado. Não vou dizer que ele tivesse a intenção de fazer isso. Mas dava cobertura ao Othon e não via o que se passava.” (CASTRO; D’ARAUJO, 2001, p. 272).

22 Respostas, já citadas, ao autor.

23 Respostas, já citadas, ao autor.

24 Depoimento ao autor em 17 de agosto de 2009.

25 Depoimento ao autor em setembro de 2011. 


\section{O Projeto do Submarino Nuclear Brasileiro}

26 Respostas, já citadas, ao autor.

27 Depoimento ao autor.

28 Depoimento, já citado, ao autor.

29 Respostas, já citadas, ao autor.

30 Agradecemos ao almirante Silvio Starling pelo envio desses dados, acompanhados do comentário: "O gráfico anexo demonstra claramente que, além de não mais recebermos as dotações orçamentárias que recebíamos, os controles que passaram a existir também contribuíram para, mesmo tendo recursos do Fundo Naval, estes não poderem ser utilizados a critério exclusivo da Marinha do Brasil." E-mail ao autor em $1^{\circ}$ de novembro de 2011. O almirante Starling foi designado pelo Comando da Marinha para facilitar o acesso do autor a dados sobre o projeto aqui analisado. Com sua ajuda, foi possível visitar, em 24 de outubro de 2011, a coordenadoria do programa, situada no Arsenal de Marinha do Rio de Janeiro, onde fomos recebidos pelo almirante Fragelli. Esta nota de agradecimento não compromete os dois almirantes com as visões aqui expostas, de exclusiva responsabilidade do autor.

31 Depoimento, já citado, ao autor.

32 Depoimento ao autor em setembro de 2011.

\section{Referências Bïbliográficas}

ALMIRANTE defende o uso de submarinos nucleares. O Estado de S. Paulo, 2 dez. 1983.

BITENCOURT, L; VAZ, A. C. Brazilian strategic culture. Miami: Florida International University, Applied Research Center, Latin American and Caribbean Center, 2009.

BRASIL pagará € 3,66 bi por submarinos. O Estado de S. Paulo, 22 ago. 2009.

BRASIL fará combustível para submarino. O Estado de S. Paulo, 28 mar. 2010.

CASTRO, C.; D’ARAUJO, M. C. Militares e política na Nova República. Rio de Janeiro: Editora FGV, 2001.

CERVO, A. L.; BUENO, C. História da política exterior do Brasil. Brasília: Editora da UNB, 2010. 
CORRÊA, F. das G. O projeto do submarino nuclear brasileiro. Rio de Janeiro: Capax Dei, 2010.

DAGNINO, R. A indústria de defesa no governo Lula. Rio de Janeiro: Expressão Popular, 2010.

ENTREVISTA com o comandante da Marinha. Tecnologia \& Defesa, v. 22, n. 106 , [s.d.].

ENTREVISTA do almirante Othon Pinheiro da Silva, atual presidente da Eletronuclear. (12/07). [s.d.]. Disponível em: <http://www.nacaodosol.org/conteudo. php? $\mathrm{a}=$ estudos\&p=32\&n=242I $>$. Acesso em: 8 mar. 2011.

ESCOLA SUPERIOR DE GUERRA - ESG. Aspectos da Doutrina da Marinha Brasileira, CSG-CEMCFA, T 304-75, 1975. [Documento reservado].

ESPELlet, E. S. Carta dos leitores. Revista Marítima Brasileira, v. 129, n. 10/12, 2009.

FLORES, M. C. Bases para uma política militar. Campinas: Editora da Unicamp, 1992.

FRANÇA construirá submarino no Brasil. O Estado de S. Paulo, 13 fev. 2008a.

FRANÇA fará estaleiro no País, diz Jobim. O Estado de S. Paulo, 23 dez. 2008b.

GOVERNO vai dar R\$ 1 bi para programa nuclear da Marinha. O Estado de S. Paulo, 11 jul. 2007.

GUIMARÃES, L. D. S. Estratégias de implementação e efeitos de arraste dos grandes programas de desenvolvimento tecnológico nacionais: experiências do Programa de Propulsão Nuclear da Marinha do Brasil. Revista Marítima Brasileira, n. 16, 2003. [Pesquisa Naval, suplemento especial da revista].

JOBIM vai à França e Rússia discutir reequipamento. O Estado de S. Paulo, 25 jan. 2008.

LIEBER, K. A. War and the engineers. Londres: Cornell University Press, 2005.

LULA marca visita a instalações da Marinha. O Estado de S. Paulo, 21 jun. 2007.

MARINHA terá submarino nuclear. O Estado de S. Paulo, 13 dez. 1983.

MARINHA instala em São Paulo fábrica de combustível nuclear para submarino. Jornal do Brasil, 4 set. 1986a.

MARINHA testará propulsão nuclear no centro de Iperó. Folha de S. Paulo, 5 set. 1986 b.

MARINHA cobra recursos para se reaparelhar. O Estado de S. Paulo, 22 jan. 2006a. 
MARINHA conclui outra fase do programa nuclear. O Estado de S. Paulo, 27 jan. 2006b.

MARTINS FILHO, J. R. Tensões militares no governo Lula: a pré-história do acordo com a França. Revista Brasileira de Ciência Política, n. 4, p. 283-306, jul./dez. 2010.

O BRASIL não quer a bomba atômica, só o submarino. O Estado de S. Paulo, 20 ago. 1986.

PETISTA defende projeto de submarino nuclear. O Estado de S. Paulo, 4 dez. 2002.

PROJETO de submarino é retomado. O Estado de S. Paulo, $1^{\circ}$ fev. 2000.

SABÓIA confirma que Brasil pesquisa combustível nuclear para submarinos. O Globo, 5 set. 1986. Disponível em: <http://www.arqanalagoa.ufscar.br/pdf/recortes/ R00533.pdf $>$. Acesso em: 18 mar. 2012.

SPEKTOR, M. Kissinger e o Brasil. Rio de Janeiro: Zahar, 2009.

SUBMARINO pode sair daqui a doze anos. O Estado de S. Paulo, 17 mai. 2009a.

SUBMARINO terá crédito de $€$ 4,3 bilhões. O Estado de S. Paulo, 14 ago. 2009b.

VIDIGAL, A. A. F; FLORES, M. C. O desenvolvimento do poder naval brasileiro: tópicos para debate. Rio de Janeiro: [s.1.], 1976.

VIGEVANI, T.; CEPALUNI, G. A política externa de Lula da Silva: a estratégia da autonomia pela diversificação. Contexto Internacional, v. 29, n. 2, p. 273 335, jul./dez. 2007.

VIZENTINI, P. G. F. O regime militar e sua política externa. In: FILHO, J. R. M. (Ed.). O golpe de 1964 e o regime militar: novas perspectivas. São Carlos: EdUFScar, 2006.

\section{Resumo}

\section{O Projeto do Submarino Nuclear Brasileiro}

$\mathrm{O}$ artigo procura reconstruir a trajetória do programa do submarino nuclear brasileiro desde suas origens, no governo Geisel, aos dias atuais. Lançando mão do conceito de oportunismo tecnológico, procura analisar a atitude dos diferentes governos federais sobre o projeto, mostrando que os governos neoliberais de Fer- 
nando Collor, Itamar Franco e Fernando Henrique Cardoso cortaram radicalmente verbas para o programa, sem, no entanto, suspendê-lo por completo. Surpreendentemente, parece haver uma continuidade entre os governos militares e o governo Lula, quanto ao apoio decidido à ideia do submarino nuclear. Quanto às relações de força na Marinha, o texto conclui que não há divergências significativas sobre a relevância do programa, o que não exclui choques de personalidades navais, em virtude do caráter autárquico assumido pelo projeto e da dificuldade de continuá-lo apenas com verbas da própria força. $\mathrm{O}$ artigo utilizou entrevistas recentes com atores-chaves do processo.

Palavras-chave: Poder Naval - Estratégia - Forças Armadas - Defesa Nacional

\section{Abstract}

\section{The Brazilian Nuclear Submarine Project}

The article aims to reconstruct the history of the Brazilian nuclear-powered submarine program, from its origins to the present. Using the concept of technological opportunism, it seeks to understand the position of the different federal administrations vis-à-vis the project, concluding that the Collor, Franco and Cardoso administrations did not support the program. However, they did not terminate the project. Surprisingly, there is a continuity between the military governments and the Lula administration, in the decisive support each gave to the program. With repect to the Navy, the analysis concludes that there were no significant disagreements, with the exception of personal conflicts originating in the autarchic features that the program had assumed and in the problem of scarcity of resources. The article is based on interviews with key actors.

Keywords: Naval Power - Strategy - Armed Forces - National Defense 